\title{
Characteristics of oral mucosal lesions and their association with socioeconomic status and systemic health in a remote rural area in China: a cross-sectional study of 146 cases
}

\section{Hui Yao}

Shanghai Jiao Tong University School of Medicine, Shanghai Jiao Tong University, National Clinical Research Center for Oral Diseases

Qiongyue Zhang

the People's Hospital of Xiangyun affiliated with Dali University

\section{Qianqian Song}

the People's Hospital of Xiangyun affiliated with Dali University

\section{Mingshan Liu}

the People's Hospital of Xiangyun affiliated with Dali University

Guoyao Tang ( $\nabla$ tanggy@shsmu.edu.cn )

Shanghai Jiao Tong University School of Medicine, Shanghai Jiao Tong University, National Clinical Research Center for Oral Diseases

\section{Research Article}

Keywords: Oral Mucosa, Ulcer, Burning mouth syndrome, Lichen planus, Rural, Socioeconomic status, Systemic health

Posted Date: January 25th, 2022

DOI: https://doi.org/10.21203/rs.3.rs-1089942/v2

License: (c) (i) This work is licensed under a Creative Commons Attribution 4.0 International License. Read Full License 


\section{Abstract \\ Background}

Epidemiological data of oral mucosal lesions (OMLs) are required to develop practical oral care policies. However, limited data are available for rural areas in China. We aimed to estimate the spectrum and prevalence of OMLs and to identify their associated socioeconomic status (SES) and systemic health in a remote rural area in Yunnan, China.

\section{Methods}

We screened patients for OMLs in an oral medicine clinic in rural Yuannan, China, from August 2020 to February 2021. OMLs were documented. SES, including the highest education level achieved and the previous month's household income, as well as the patient's systemic health, including a history of smoking, alcohol use, and chronic disease, were obtained from the Medical History/Health Questionnaire Form and patient medical records.

\section{Results}

A total of 146 patients were found to have OMLs. The most frequent OML was aphthous ulcer $(n=41$, $28.1 \%)$, followed by burning mouth syndrome (BMS) $(n=16,11.0 \%)$, viral ulcer $(n=14,9.6 \%)$, and oral lichen planus (OLP) $(n=9,6.2 \%)$. In these patients, the most common chronic diseases were sleep apnea ( $n=35,24.0 \%$ ), hypertension ( $n=23,15.8 \%$ ), bronchitis $(n=16,11.0 \%)$, reflux (including gastroesophageal reflux disease) $(n=12,8.2 \%)$, and arthritis $(n=11,7.5 \%)$. On adjusted regression, the patients without chronic diseases had a lower risk of BMS than those with chronic diseases (odds ratio [OR], 0.2; 95\% confidence interval [CI], 0.03-0.9). Age was an independent protective factor for viral ulcers $(\mathrm{OR}, 1.0 ; 95 \% \mathrm{Cl}, 0.9-1.0)$. Patients with low-income levels had a lower risk of OLP than those with highincome levels (OR, 0.2; $95 \% \mathrm{Cl}, 0.05-0.9)$.

\section{Conclusions}

In rural Yunnan in China, the most frequent OML was aphthous ulcer, which was followed by BMS, viral ulcer, and OLP. Chronic diseases were associated with BMS. Age was an independent protective factor for oral viral ulcers. A high-income level was associated with the presence of OLP. Oral care policies should be prioritized among patients with aphthous ulcer. Preventive strategy of BMS should be targeted to people with chronic disease for health equalities.

\section{Background}


Oral mucosal lesions (OMLs) include various disorders involving the oral mucosa, affecting $4.9-64.7 \%$ of people in the general population worldwide [1]. Some lesions can impair chewing, swallowing, and speaking functions [2], while others may influence systemic health [3] or progress to oral cancer [4]. The Chinese government released the Healthy China 2030 blueprint to guide the healthcare promotion [5]. Oral health is an important part of this blueprint. To promote oral health, manage oral diseases, and develop an oral care strategy, it is urgent for governments to understand local epidemiological characteristics of OMLs.

In the rural areas, patients with OMLs often suffer more due to their difficulty with accessing appropriate oral healthcare in a timely manner. The epidemiology of OMLs is also not well characterized in remote rural areas due to a lack of local oral specialists. Recently, the Shanghai and Yunnan governments organized a program for oral specialists to temporarily work in these rural areas and perform free oral examinations in the local population. This provides an opportunity to understand the characteristics of OMLs in local rural areas.

In this study, we aimed to determine the spectrum and frequency of OMLs along with their possible associations with socioeconomic status (SES) and systemic health in a remote rural area in Yunnan, China. Our study results provide preliminary epidemiological data for policy making to improve oral hygiene in this local rural area in China.

\section{Methods}

\section{Study setting and participants}

The present study was performed in a rural Oral Medicine Clinic ran by the Department of Stomatology, the People's Hospital of Xiangyun affiliated with Dali University, China. This clinic included an oral medicine specialist who stationed, practiced, and trained two general dentists there between August 2020 and February 2021. With the support of the poverty-alleviation program collaborated by Shanghai and Yunnan, the specialist worked there and provided free oral examinations. The ethics committee of the People's Hospital of Xiangyun approved this study (no. 2020069). All patients and/or their guardians signed informed consent. We included all patients with OMLs and excluded all visitors without OMLs.

\section{Data collection}

A single-clinic cross-sectional study was performed including the first 146 patients, who arrived for their first oral medicine visit between August 2020 to and February 2021. We excluded 2 visitors, who came for check-ups with no abnormal findings.

During their visits, all patients filled an SES form and reported the details of their systemic health using the Medical History/Health Questionnaire Form from the Center for Oral Medicine, College of Dental Medicine, Augusta University, Georgia, USA.Items in theSES included the highest education level achieved and the previous month's household income. Systemic health variables included a history of smoking, 
alcohol use, and chronic disease. These variables were used as exposures to analyze whether they were associated with OML outcomes.

The diagnostic criteria for OMLs were based on the fourth edition of Oral and Maxillofacial Pathology authored by Neville B. et al. In the dental office, an oral examination was performed under a dental chair light with the patient sitting on the chair. The specialist inspected and palpated using tools including a mirror, explorer, cotton swab, and sterile gauze. The specialist adopted the following examination sequence: face, lip, buccal, tongue, mouth floor, hard palate, soft palate, gum, and alveolar ridge. When the diagnosis was uncertain, we marked "diagnostic uncertainty" in the medical records due to a lack of oral pathology or other laboratory services in the rural hospital.

\section{Statistical analysis}

Age is presented as a median with interquartile range (IQR). Categorical variables are presented as numbers with percentages (\%). Unadjusted or adjusted regression analyses were performed to analyze the risk factors (sex, age, education, the last-month household income, smoking, alcohol use, and chronic disease) associated with the presence of OMLs. Statistical analyses were conducted using SPSS software (version 26.0, IBM Corporation, Armonk, NY, USA). Statistical significance was set at $P<.05$.

\section{Results}

A total of 146 patients were enrolled in this study, including 77 (52.7\%) women and 69 (47.3\%) men, with a median age of 51.5 years (IQR, 30.8-65.0 years). These patients were mostly Han ethnicity $(n=132$, $90.4 \%)$, native residents $(n=134,91.8 \%)$, and living in villages $(n=117,80.1 \%)$. Nearly $75 \%$ of the patients had not graduated from high school $(n=107,77.0 \%)$ and did not earn more than 6,000 yuan as a household income in the previous month $(n=99,73.9 \%)$. Approximately $25 \%$ of the patients had a history of smoking $(n=35,24.8 \%)$ or alcohol use $(n=36,25.5 \%)$.

Eighty-six (58.9\%) patients had a history of chronic disease (Table 1). Table 2 shows the distribution of chronic diseases. The most common chronic diseases were sleep apnea $(n=35,24.0 \%)$, hypertension ( $n$ $=23,15.8 \%$ ), bronchitis (including emphysema) $(n=16,11.0 \%)$, reflux (including gastroesophageal reflux disease) $(n=12,8.2 \%)$, and arthritis $(n=11,7.5 \%)$. Forty-three (29.5\%) patients had more than one chronic disease. 
Table 1

Characteristics of patients.

n $\quad \%$

\section{Sex}

Female

77

52.7

Male

Age, years, N (IQR)

69

47.3

$51.5(30.8-65.0)$

\section{Ethnicity}

Han

132

90.4

Others

Education* (highest level achieved)

Less than high school

107

77.0

High school and above

32

23.0

\section{Last-month household income*}

Less than 6,000 yuan

99

73.9

6,000 yuan and above

35

26.1

\section{Primary residence}

Native county

Nearby county or migrant

Settled place

Village

117

80.1

Town or city

29

19.9

\section{Smoking*}

No

106

75.2

Yes

35

24.8

\section{Alcohol use ${ }^{\star}$}

No

105

74.5

Data are shown as $\mathrm{n}$ (\% of available data) or median (interquartile range). The total number of patients was 146. *Missing data: education, $n=7$; last-month household income, $n=12$; smoking, $n=$ 5; alcohol use, $n=5$. 


\begin{tabular}{|lcc|}
\hline & $\mathbf{n}$ & $\%$ \\
\hline Yes & 36 & 25.5 \\
\hline Chronic disease & & \\
\hline No & 60 & 41.1 \\
\hline Yes & 86 & 58.9 \\
\hline $\begin{array}{l}\text { Data are shown as } \mathrm{n} \text { (\% of available data) or median (interquartile range). The total number of } \\
\text { patients was 146. *Missing data: education, } n=7 \text {; last-month household income, } n=12 ; \text { smoking, } n= \\
\text { 5; alcohol use, } n=5 .\end{array}$ \\
\hline
\end{tabular}


Table 2

Distributions of chronic diseases.

\begin{tabular}{|c|c|c|}
\hline Chronic diseases & $\mathbf{n}$ & $\%$ \\
\hline Respiratory problems & 55 & 37.7 \\
\hline Asthma & 3 & 2.1 \\
\hline Tuberculosis & 1 & 0.7 \\
\hline Sleep apnea & 35 & 24.0 \\
\hline Bronchitis/emphysema & 16 & 11.0 \\
\hline Hematologic problems & 16 & 11.0 \\
\hline Anemia & 8 & 5.5 \\
\hline HIV/AIDS & 1 & 0.7 \\
\hline Warfarin treatment & 3 & 2.1 \\
\hline Others & 4 & 2.7 \\
\hline Cardiovascular problems & 31 & 21.2 \\
\hline Hypertension & 23 & 15.8 \\
\hline Angina/chest pain & 1 & 0.7 \\
\hline Heart attack/myocardial infarction & 1 & 0.7 \\
\hline Prosthetic (artificial) heart valve & 1 & 0.7 \\
\hline Others & 5 & 3.4 \\
\hline Gastrointestinal problems & 20 & 13.7 \\
\hline Hepatitis/jaundice & 2 & 1.4 \\
\hline GERD/reflux & 12 & 8.2 \\
\hline Others & 6 & 4.1 \\
\hline Neurological problems & 19 & 13.0 \\
\hline Stroke/TIA/mini-stroke & 9 & 6.2 \\
\hline Neuropathy/neuropathic pain & 4 & 2.7 \\
\hline Others & 6 & 4.1 \\
\hline Endocrine problems & 14 & 9.6 \\
\hline
\end{tabular}

Abbreviations: AIDS, acquired immunodeficiency syndrome; GERD, gastroesophageal reflux disease; HIV, human immunodeficiency virus; TIA, transient ischemic attack. 


\begin{tabular}{|lcc|}
\hline Chronic diseases & $\mathbf{n}$ & $\%$ \\
\hline Diabetes & 9 & 6.2 \\
\hline Thyroid disorder & 3 & 2.1 \\
\hline Others & 2 & 1.4 \\
\hline Kidney disease or dialysis & 2 & 1.4 \\
\hline Cancer & 1 & 0.7 \\
\hline Radiation therapy & 1 & 0.7 \\
\hline Chemotherapy & 1 & 0.7 \\
\hline Arthritis & 11 & 7.5 \\
\hline Sjögren's syndrome & 1 & 0.7 \\
\hline $\begin{array}{l}\text { Abbreviations: AIDS, acquired immunodeficiency syndrome; GERD, gastroesophageal reflux disease; } \\
\text { HIV, human immunodeficiency virus; TIA, transient ischemic attack. }\end{array}$ \\
\hline
\end{tabular}

A total of 23 types of OMLs were found in 146 patients, including three patients who had two types of OMLs. The most common OMLs were aphthous ulcer $(n=41,28.1 \%)$, burning mouth syndrome (BMS) ( $n$ $=16,11.0 \%)$, viral ulcer $(n=14,9.6 \%)$, traumatic ulcer $(n=13,8.9 \%)$, and oral lichen planus (OLP) $(n=9$, 6.2\%) (Table 3). 
Table 3

Frequencies of oral mucosal lesions.

\begin{tabular}{|lll|}
\hline Oral mucosal lesions & $\mathbf{n}$ & $\%$ \\
\hline Allergy & 3 & 2.1 \\
\hline Angular cheilitis & 2 & 1.4 \\
\hline Bacteria & 1 & 0.7 \\
\hline Burning mouth syndrome & 16 & 11.0 \\
\hline Fungus & 4 & 2.7 \\
\hline Geographic tongue & 3 & 2.1 \\
\hline Gingival condition & 2 & 1.4 \\
\hline Glossitis & 4 & 2.7 \\
\hline Hematoma & 4 & 2.7 \\
\hline Hyperkeratosis & 1 & 0.7 \\
\hline Lump & 6 & 4.1 \\
\hline Mucositis & 2 & 1.4 \\
\hline Neuropathic pain & 3 & 2.1 \\
\hline Oral cancer & 2 & 1.4 \\
\hline Oral dryness & 2 & 1.4 \\
\hline Oral lichen planus & 9 & 6.2 \\
\hline Oral submucous fibrosis & 1 & 0.7 \\
\hline Oral ulcer & 80 & 54.8 \\
\hline Aphthous ulcer & 41 & 28.1 \\
\hline Traumatic ulcer & 13 & 8.9 \\
\hline Viral ulcer & 14 & 9.6 \\
\hline Unclassified ulcer & 12 & 8.2 \\
\hline Pigmentation & 1 & 0.7 \\
\hline Uncertainty & 3 & 2.1 \\
\hline
\end{tabular}

On unadjusted regression, the patients without chronic diseases had a 20\% (95\% confidence interval [CI], 0.04-0.8) lower risk of BMS than the patients with chronic diseases. After adjustment for sex, age, education, last-month household income, smoking, and alcohol use, those without chronic diseases still had a $20 \%(95 \% \mathrm{Cl}, 0.03-0.9)$ lower risk of BMS than those with chronic diseases. A similarly decreased 
risk (odds ratio [OR], $0.2 ; 95 \% \mathrm{Cl}, 0.05-0.9$ ) of OLP was observed for the previous month's household income of less than 6,000 yuan adjusted for the covariates, including sex, age, education, smoking, alcohol use, and chronic diseases (Table 4). The protective factor independently associated with viral ulcer was an older age $(\mathrm{OR}, 1.0 ; 95 \% \mathrm{Cl}, 0.9-1.0)$. Non-smoking was associated with a significantly increased risk (OR, 2.9; $95 \% \mathrm{Cl}, 1.0-8.0)$ of aphthous ulcer on unadjusted regression. After adjustment for sex, age, education, last-month household income, alcohol use, and chronic disease, no association was found between smokers and non-smokers. Similarly, patients without chronic diseases were associated with an increased risk (OR, 4.1; 95\% $\mathrm{Cl}, 1.2-13.8)$ of developing viral ulcers on unadjusted regression. However, after adjusting the analysis for sex, age, education, last-month household income, smoking, and alcohol use, this association disappeared (Table 5). 
Table 4

Characteristics associated with burning mouth syndrome or oral lichen planus.

\section{Characteristics Burning mouth syndrome}

$$
\begin{array}{lllllll}
\text { Unadjusted } & P & \begin{array}{l}
\text { Adjusted } \\
\text { OR }(95 \% \\
\text { OR }(95 \% \mathrm{Cl})
\end{array} & P & \begin{array}{l}
\text { Unadjusted } \\
\text { OR }(95 \% \mathrm{Cl})
\end{array} & P & \begin{array}{l}
\text { Adjusted } \\
\text { OR }(95 \% \\
\mathrm{Cl})
\end{array}
\end{array} \quad P
$$

\begin{tabular}{|c|c|c|c|c|c|c|c|c|}
\hline Female & $\begin{array}{l}0.9(0.3- \\
2.4)\end{array}$ & .77 & $\begin{array}{l}2.2(0.4- \\
13.3)\end{array}$ & .39 & $\begin{array}{l}0.4(0.1- \\
1.8)\end{array}$ & .24 & $\begin{array}{l}0.4(0.1- \\
2.4)\end{array}$ & .31 \\
\hline Age* $^{*}$ & $\begin{array}{l}1.0(1.0- \\
1.0)\end{array}$ & .15 & $\begin{array}{l}1.0(1.0- \\
1.0)\end{array}$ & .80 & $\begin{array}{l}1.0(1.0- \\
1.1)\end{array}$ & .19 & $\begin{array}{l}1.0(1.0- \\
1.1)\end{array}$ & 1 \\
\hline
\end{tabular}

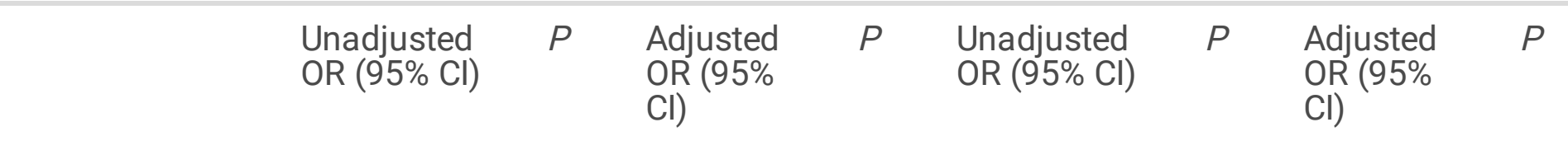

\section{Sex}

\section{Education†}

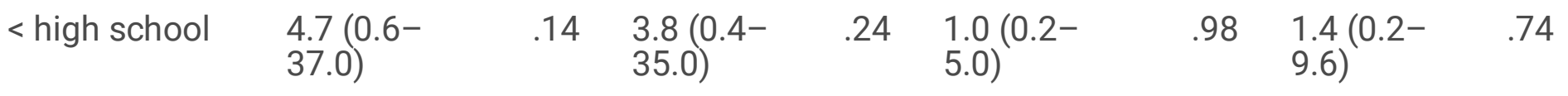

\section{Incomeł}

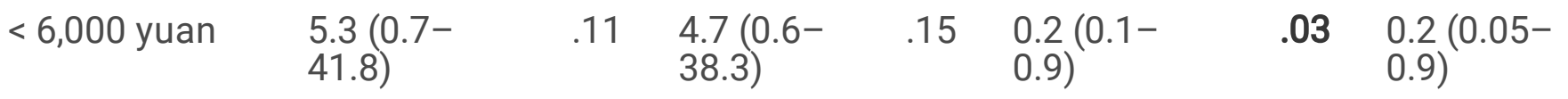

\section{Smoking}

No

$0.7(0.2-$

2.1)
.47

$0.6(0.1-$

4.6)
$0.6(0.2-$

2.6)
$.51 \quad 0.6(0.2-$

2.7)
$0.6(0.1-$

2.6)
.50

$1.4(0.2-$ 11.6)

\section{Alcohol use}

No

$0.5(0.2-$

1.5)

.21

\section{Chronic diseases}

No
$0.2(0.04-$
$0.8)$

.03

$0.2(0.03-$

$0.9)$

$.04 \quad 0.4(0.1-$

1.9)

.25

$0.6(0.1-$

4.1)

$0.9(0.1-$

.92

6.3)

Abbreviations: $\mathrm{OR}$, odds ratio; $\mathrm{Cl}$, confidence interval. *Age (years); †Education (highest level achieved); ‡Income (last-month household). Adjusted for sex, age, education, income, smoking, alcohol use, and chronic disease. The references were male gender, $\geq$ high school education, $\geq 6,000$ yuan income, yes to smoking, yes to alcohol, and yes to chronic diseases. 
Table 5

Characteristics associated with aphthous ulcer or viral ulcer

Aphthous ulcer

Unadjusted

OR $(95 \% \mathrm{Cl})$
$P$

Adjusted OR $(95 \% \mathrm{Cl})$
Viral ulcer

Unadjusted $\quad P \quad$ Adjusted $P$

OR $(95 \% \mathrm{Cl})$

OR $(95 \%$

$\mathrm{Cl})$

\section{Sex}

\begin{tabular}{|c|c|c|c|c|c|c|c|c|}
\hline Female & $2.1(1.0-4.5)$ & .05 & $\begin{array}{l}1.7(0.7- \\
4.2)\end{array}$ & .29 & $1.7(0.5-5.3)$ & .37 & $\begin{array}{l}3.6(0.7- \\
19.5)\end{array}$ & .14 \\
\hline $\mathrm{Age}^{*}$ & $1.0(1.0-1.0)$ & .68 & $\begin{array}{l}1.0(1.0- \\
1.0)\end{array}$ & .70 & $1.0(0.9-1.0)$ & .01 & $\begin{array}{l}1.0(0.9- \\
1.0)\end{array}$ & .04 \\
\hline
\end{tabular}

\section{Education†}

\begin{tabular}{|c|c|c|c|c|c|c|c|}
\hline $\begin{array}{l}<\text { high } \\
\text { school }\end{array}$ & $0.6(0.2-1.3)$ & .18 & $\begin{array}{l}0.5(0.2- \\
1.3)\end{array}$ & .14 & $0.7(0.2-2.3)$ & .5 & $\begin{array}{l}1.0(0.2- \\
3.6)\end{array}$ \\
\hline
\end{tabular}

Incomeł

\begin{tabular}{|c|c|c|c|c|c|c|c|}
\hline $\begin{array}{l}<6,000 \\
\text { yuan }\end{array}$ & $1.0(0.4-2.3)$ & .94 & $\begin{array}{l}1.0(0.4- \\
2.5)\end{array}$ & .96 & $0.8(0.2-2.6)$ & .67 & $\begin{array}{l}1.0(0.2- \\
4.0)\end{array}$ \\
\hline
\end{tabular}

\section{Smoking}

No

$2.9(1.0-8.0)$

$\begin{array}{ll}.04 & 2.0(0.5- \\ 8.0)\end{array}$

$.33 \quad 1.2(0.3-4.5)$

.82

0.4

(0.03-

\section{Alcohol}

use

No

$1.9(0.7-4.6)$

.19

$1.0(0.3-$

.99

3.1)

$0.8(0.2-2.7)$

.72

$0.5(0.1-$

.40

\section{Chronic diseases}

No

$$
\begin{array}{lll}
1.3(0.7-2.8) \quad .42 & 1.3(0.5- \\
& 3.0)
\end{array}
$$

.61

4.1 (1.2-

13.8)

$.02 \quad 2.6(0.6-$

.18

Abbreviations: $\mathrm{OR}$, odds ratio; $\mathrm{Cl}$, confidence interval. *Age (years); †Education (highest level achieved); ‡Income (last-month household). Adjusted for sex, age, education, income, smoking, alcohol use, and chronic disease. The references were male gender, $\geq$ high school education, $\geq 6,000$ yuan income, yes to smoking, yes to alcohol, and yes to chronic diseases.

\section{Discussion}


In this study, we found the most common OMLs were aphthous ulcer, BMS, and viral ulcer. The most common comorbidities were sleep apnea, hypertension, and bronchitis (including emphysema). Patients with chronic diseases had a higher prevalence of BMS compared without those without chronic diseases. A household income of less than 6,000 yuan was an independent risk factor for OLP. These major findings can provide practical information for the government to optimize medical resources during the prevention and intervention of OMLs in remote rural areas where oral services are limited.

In terms of the relative frequency of OMLs, findings vary in the literature due to different diagnostic criteria, participants, and study methods. Patients with or without pathogen cultures and histopathological examinations might have different diagnoses. The use of a community-based survey or a medical records review could also cause certain analysis biases, such as participants enrolled. Overall, aphthous ulcer, BMS, and OLP were the most frequent OMLs [6, 7]. Oral submucous fibrosis was not found in our study, but its frequency is high in some regions of China, such as Hunan [8], probably due to the common habit of chewing betel nuts. The present study also showed that $24.0 \%$ our study population had sleep apnea, which was the most common comorbidity. This is consistent with the prevalence of sleep apnea in the general population [9]. Other common comorbidities were hypertension, bronchitis (including emphysema), reflux (including gastroesophageal reflux disease), and arthritis. The life and work routines might explain the frequency of comorbid diseases. People in our survey area had a high prevalence of sleep apnea and were more likely to have frequent smoking and/or drinking habits, which increased their risk for hypertension. A certain number of people in our survey area smoked and worked in the mining industry; thus, it is common for them to have lung diseases. Reflux mostly affected people who work in mountains for extended periods and skipped their meals. Prolonged standing or lengthy climbing up and down during work increases the risk of arthritis. This finding about comorbidities was also consistent to the spectrum of chronic disease in a study from China [10].

Aphthous ulcer is among the most common OMLs, with a prevalence of approximately $20 \%$ [11] and an incidence ranging from $5-50 \%$ [12]. Smoking is its protective factor $[13,14]$. Our study also supported such relationship between smoking and aphthous ulcer on unadjusted regression analysis. However, this association disappeared after adjusting for multiple confounders. The reason for this loss might be that the causes of aphthous ulcer were comprehensive and multifactorial, including a genetic background, stress, and nutritional deficiencies [15]. Viral ulcers in the mouth affected more than $85 \%$ of adults [16]. Additionally, $40 \%$ of patients with primary herpetic simplex virus (HSV) experienced recurrent HSV infection [17]. There was a significant age-related decrease in the frequency of viral ulcer after adjusting for sex, the highest education level achieved, the previous month's household income, smoking, alcohol use, and chronic diseases in our study. The reason for this might be because primary HSV infection was common in children aged six months to five years and young adults aged 20 years [18]. Some associations were found between chronic disease and viral ulcer on unadjusted regression. The explanation for this association could be that recurrent HSV infection happened from its latent forms in the trigeminal ganglions during a host's immunocompromised or immunosuppressed state $[19,20]$. However, no interaction was identified between chronic disease and viral ulcer in the context of sex, age, highest education level achieved, previous-month household income, smoking, or alcohol use. It is 
notable that oral viral ulcers can also happen in patients without chronic diseases. The causal relationship between oral viral ulcers and chronic disease requires further investigation.

The prevalence of BMS in the general population was estimated to be between $0.7 \%$ and $8 \%$ based on different diagnostic criteria [21, 22]. In the current study, we found that chronic disease increased the risk of developing BMS after adjusting for sex, age, highest education level achieved, previous-month household income, smoking, and alcohol use. The reason for this could be that systemic factors, including anemia, diabetes, thyroid disease, hormonal deficiency, upper respiratory tract infection, gastroesophageal reflex disease, Parkinson's disease, and side effects of antihypertensive medications, were associated with BMS [23].

OLP is a chronic inflammatory condition, which is a common mucocutaneous disorder in the oral cavity. The prevalence of OLP was estimated to be between 1\% and 3\% [24]. Systemic factors, such as hypertension, diabetes, viral infection, autoimmunity or immunodeficiency, and cancer, were supposed to be its etiology [24]. Patients with OLP had significantly higher prevalence of stress, anxiety, and depression than the general population [25-27]. A chronic and long-lasting course of OLP could make patients stressed, anxious, and depressed. Meanwhile, stress, anxiety, and depression could lead to the development of OLP. Furthermore, there might be an association between depression and high income, although this suggestion contradicted other study results [28-30]. People with high incomes may perform high-pressure work in a competitive environment. Depressed individuals with high income levels may have an increased risk for developing OLP. However, this association should be treated with caution because chronic disease can reduce the associations of SES factors, such as income, with depression [28-30]. The underlying mechanism needs to be explored further.

Our study had some limitations. The small sample size could cause biases in our result analysis. Some patients might have oral lichenoid lesions that were difficult to distinguish from OLP without laboratory confirmation. Therefore, the frequency of OLP might be overestimated. All diagnoses were made by one single specialist. Thus, the reliability of the diagnoses might be weakened.

\section{Conclusions}

In conclusion, we demonstrated the frequency of different OMLs in rural Yunnan and found that aphthous ulcer was the most common OML, which was followed by BMS, viral ulcers, and OLP. Older age had a decreased risk for oral viral ulcers. Chronic diseases were associated with a significant increase in BMS, and a high-income level was associated with OLP. Priority of oral care policies should be given to patients with aphthous ulcer. Preventive interventions of BMS should be developed among people with chronic disease.

\section{Abbreviations}

OML 
oral mucosal lesion

SES

socioeconomic status

BMS

burning mouth syndrome

OLP

oral lichen planus

HSV

herpetic simplex virus

OR

odds ratio

$\mathrm{Cl}$

confidence interval

\section{Declarations}

\section{Ethics approval and consent to participate}

We have confirmed that the study protocol was approved by the ethics committee of the People's Hospital of Xiangyun (no. 2020069) and informed consent was obtained from all patients and/or their guardians. We have also confirmed that all methods were carried out in accordance with the ethical standards in the 1964 Declaration of Helsinki and its later amendments or comparable ethical standards.

\section{Consent for publication}

Not applicable. No personal information was provided in this paper.

\section{Availability of data and materials}

The data and materials collected in this research are not publicly available due to privacy and ethical restrictions. But they are available from the corresponding author upon reasonable request.

\section{Competing interests}

The authors reported no competing interests.

\section{Funding}

This study had no funding.

\section{Authors contributions}

H. Y., M. L., and G. T. formulated the conception and designed the study. H. Y., Q. Z., Q. S., and M. L. acquired, analyzed, and interpreted the data. G. T. and H. Y. drafted the manuscript. All authors have 
reviewed and approved the manuscript.

\section{Acknowledgments}

We thank LetPub (www.letpub.com) for linguistic assistance and pre-submission expert review.

\section{References}

1. Feng J, Zhou Z, Shen X, Wang Y, Shi L, Wang Y, et al. Prevalence and distribution of oral mucosal lesions: a cross-sectional study in Shanghai, China. J Oral Pathol Med. 2015;44(7):490-4; doi: 10.1111/jop.12264.

2. Triantos D. Intra-oral findings and general health conditions among institutionalized and noninstitutionalized elderly in Greece. J Oral Pathol Med. 2005;34(10):577-82; doi: 10.1111/j.16000714.2005.00356.x.

3. Tavares M, Lindefjeld Calabi KA, San Martin L. Systemic diseases and oral health. Dent Clin North Am. 2014;58(4):797-814; doi: 10.1016/j.cden.2014.07.005.

4. Chher T, Hak S, Kallarakkal TG, Durward C, Ramanathan A, Ghani WMN, et al. Prevalence of oral cancer, oral potentially malignant disorders and other oral mucosal lesions in Cambodia. Ethn Health. 2018;23(1); doi: 10.1080/13557858.2016.1246431.

5. Zhou X, Xu X, Li J, Hu D, Hu T, Yin W, et al. Oral health in China: from vision to action. Int J Oral Sci. 2018;10(1):1; doi: 10.1038/s41368-017-0006-6.

6. Hong CHL, Dean DR, Hull K, Hu SJ, Sim YF, Nadeau C, et al. World Workshop on Oral Medicine VII: Relative frequency of oral mucosal lesions in children, a scoping review. Oral Dis. 2019;25 Suppl 1:193-203; doi: 10.1111/odi.13112.

7. Zhou N, Zhang X, Yan J-Q, Yu Y-Q, Cai Y. Prevalence of Oral Mucosal Diseases in Older Adults in Mainland China: A Meta-Analysis of Observational Studies. Int J Environ Res Public Health. 2020;17(6); doi: 10.3390/ijerph17061887.

8. Wang $\mathrm{H}, \mathrm{He} F$, Xu C, Fang C, Peng J. [Clinical analysis for oral mucosal disease in 21972 cases]. Zhong Nan Da Xue Xue Bao Yi Xue Ban. 2018;43(7):779-83; doi: 10.11817/j.issn.16727347.2018.07.013.

9. Heinzer R, Vat S, Marques-Vidal P, Marti-Soler H, Andries D, Tobback N, et al. Prevalence of sleepdisordered breathing in the general population: the HypnoLaus study. Lancet Respir Med. 2015;3(4):310-8; doi: 10.1016/S2213-2600(15)00043-0.

10. Yu X, Zhang W. Neighborhood's locality, road types, and residents' multimorbidity: evidence from China's middle-aged and older adults. BMC Public Health. 2020;20(1):1728; doi: 10.1186/s12889020-09876-y.

11. Akintoye SO, Greenberg MS. Recurrent aphthous stomatitis. Dent Clin North Am. 2014;58(2):281-97; doi: 10.1016/j.cden.2013.12.002. 
12. Cui RZ, Bruce AJ, Rogers RS, 3rd. Recurrent aphthous stomatitis. Clin Dermatol. 2016;34(4):475-81; doi: 10.1016/j.clindermatol.2016.02.020.

13. Rivera-Hidalgo F, Shulman JD, Beach MM. The association of tobacco and other factors with recurrent aphthous stomatitis in an US adult population. Oral Dis. 2004;10(6):335-45; doi: 10.1111/j.1601-0825.2004.01049.x.

14. Chattopadhyay A, Chatterjee S. Risk indicators for recurrent aphthous ulcers among adults in the US. Community Dent Oral Epidemiol. 2007;35(2):152-9; doi: 10.1111/j.1600-0528.2007.00329.x.

15. Bilodeau EA, Lalla RV. Recurrent oral ulceration: Etiology, classification, management, and diagnostic algorithm. Periodontol 2000. 2019;80(1):49-60; doi: 10.1111/prd.12262.

16. Eisen $D$. The clinical characteristics of intraoral herpes simplex virus infection in 52 immunocompetent patients. Oral Surg Oral Med Oral Pathol Oral Radiol Endod. 1998;86(4):432-7; doi: 10.1016/s1079-2104(98)90369-9.

17. Fitzpatrick SG, Cohen DM, Clark AN. Ulcerated Lesions of the Oral Mucosa: Clinical and Histologic Review. Head Neck Pathol. 2019;13(1):91-102; doi: 10.1007/s12105-018-0981-8.

18. Kolokotronis A, Doumas S. Herpes simplex virus infection, with particular reference to the progression and complications of primary herpetic gingivostomatitis. Clin Microbiol Infect. 2006;12(3):202-11; doi: 10.1111/j.1469-0691.2005.01336.x.

19. Cohen SG, Greenberg MS. Chronic oral herpes simplex virus infection in immunocompromised patients. Oral Surg Oral Med Oral Pathol. 1985;59(5):465-71; doi: 10.1016/0030-4220(85)90085-4.

20. Baringer JR, Swoveland P. Recovery of herpes-simplex virus from human trigeminal ganglions. $\mathrm{N}$ Engl J Med. 1973;288(13):648-50; doi: 10.1056/NEJM197303292881303.

21. Zakrzewska J, Buchanan JA. Burning mouth syndrome. BMJ Clin Evid. 2016;2016.

22. Bergdahl $M$, Bergdahl J. Burning mouth syndrome: prevalence and associated factors. J Oral Pathol Med. 1999;28(8):350-4; doi: 10.1111/j.1600-0714.1999.tb02052.x.

23. Klein B, Thoppay JR, De Rossi SS, Ciarrocca K. Burning Mouth Syndrome. Dermatol Clin. 2020;38(4):477-83; doi: 10.1016/j.det.2020.05.008.

24. Nogueira PA, Carneiro S, Ramos-e-Silva M. Oral lichen planus: an update on its pathogenesis. Int J Dermatol. 2015;54(9):1005-10; doi: 10.1111/ijd.12918.

25. Manczyk B, Golda J, Biniak A, Reszelewska K, Mazur B, Zajac K, et al. Evaluation of depression, anxiety and stress levels in patients with oral lichen planus. J Oral Sci. 2019;61(3):391-7; doi: 10.2334/josnusd.18-0113.

26. De Porras-Carrique T, Gonzalez-Moles MA, Warnakulasuriya S, Ramos-Garcia P. Depression, anxiety, and stress in oral lichen planus: a systematic review and meta-analysis. Clin Oral Investig. 2021; doi: 10.1007/s00784-021-04114-0.

27. Adamo D, Ruoppo E, Leuci S, Aria M, Amato M, Mignogna MD. Sleep disturbances, anxiety and depression in patients with oral lichen planus: a case-control study. J Eur Acad Dermatol Venereol. 2015;29(2):291-7; doi: 10.1111/jdv.12525. 
28. Lei X, Sun X, Strauss J, Zhang P, Zhao Y. Depressive symptoms and SES among the mid-aged and elderly in China: evidence from the China Health and Retirement Longitudinal Study national baseline. Soc Sci Med. 2014;120:224-32; doi: 10.1016/j.socscimed.2014.09.028.

29. Lu S, Reavley N, Zhou J, Su J, Pan X, Xiang Q, et al. Depression among the general adult population in Jiangsu Province of China: prevalence, associated factors and impacts. Soc Psychiatry Psychiatr Epidemiol. 2018;53(10):1051-61; doi: 10.1007/s00127-018-1568-0.

30. Wang Z, Yang H, Guo Z, Liu B, Geng S. Socio-demographic characteristics and co-occurrence of depressive symptoms with chronic diseases among older adults in China: the China longitudinal ageing social survey. BMC Psychiatry. 2019;19(1):310; doi: 10.1186/s12888-019-2305-2. 